\title{
The feasibility of complete anatomical correction in the setting of discordant atrioventricular connections
}

C Alva, E Horowitz, S Y Ho, M L Rigby, R H Anderson

\begin{abstract}
Objective-To evaluate the feasibility of anatomical correction based on morphological and echocardiographic findings in patients and preserved hearts with discordant atrioventricular connections. Design-A retrospective study with clinicomorphological correlations to assess potential contraindications for anatomical correction in the setting of discordant atrioventricular connections.

Setting-A tertiary referral centre for congenital heart disease.

Material-25 specimens and 53 patients unified by presence of discordant atrioventricular connections.

Methods-The potential contraindications for anatomical correction were first evaluated on the basis of morphological findings in all 25 specimens with discordant atrioventricular connections collected in the department museum, including study of the major coronary arterial patterns in 20. These contraindications were then sought in a population of 53 patients examined echocardiographically between January 1992 and October 1997.
\end{abstract}

Results-At least one lesion was discovered that might have contraindicated anatomical correction in 14 of the specimens and in 16 of the patients. The most common lesions that might militate against the anatomical approach were severe Ebstein's malformation or straddling and overriding of the tricuspid valve, each when combined with hypoplasia of the morphologically right ventricle. Other potential contraindications were atrioventricular septal defect with common atrioventricular junction, and obstruction of the left ventricular outlet combined with a restrictive ventricular septal defect, although these may be overcome with increasing experience and expertise.

Conclusions-According to the morphological and echocardiographic findings, at least 10 hearts and 37 patients would have produced no anatomical problems for the type of surgical correction in which the morphologically left ventricle is restored its rightful role as the systemic pumping chamber.

(Heart 1999;81:539-545)

Keywords: atrioventricular discordant connections; congenitally corrected transposition; double switch operation
It is now more than 100 years since Von Rokitansky ${ }^{1}$ coined the term "corrected transposition." Since then, the characteristic morphology of this fascinating lesion, with discordant atrioventricular connections as its primary feature, has been well described..$^{2-5}$ Attention has appropriately been focused on complicating factors, such as obstruction in the ventricular outflow tracts, ${ }^{67}$ straddling of the atrioventricular valves, ${ }^{8}$ and the abnormal disposition of the atrioventricular conduction tissues. ${ }^{9}{ }^{10}$ These studies have established that the potential "physiological" correction of the circulation produced by the presence of discordant connections at both atrioventricular and ventriculo-arterial junctions is usually "uncorrected" by the associated malformations.

In the present era, it would seem a simple matter to correct these malformations surgically, and thus restore the physiologically corrected circulation. Despite much experience, however, the results of simple repair of the intracardiac lesions, when viewed over the longer term, have been less than ideal. The rates of operative mortality, the incidence of tricuspid valvar replacement, and the iatrogenic production of atrioventricular block all remain alarmingly high. Furthermore, failure of the morphologically right ventricle is by no means uncommon in the long term. ${ }^{11}{ }^{12}$ Thus, although extended survival into adult life would be expected, ${ }^{13}$ Connelly and coworkers ${ }^{14}$ found that, in those undergoing "classical" surgery in Toronto, one quarter had died by the end of their fourth decade. Furthermore, many of the survivors showed progressive atrioventricular block, arrhythmias, and left atrioventricular valvar regurgitation. These findings lend support to the long held suspicion that, in time, the morphologically right ventricle will fail when called upon to support the systemic circulation.

Considerations of this kind prompted Ilbawi et al to seek an alternative surgical approach. ${ }^{15}$ They combined an atrial switch with the Rastelli procedure, thus recruiting the morphologically left ventricle as the systemic ventricle. This approach, producing both physiological and anatomical correction, has now evolved to include a further combination of procedures. In patients with a normal pulmonary valve, the atrial switch is combined with an arterial switch. In this setting, if the morphologically left ventricle is not capable of supporting the systemic circulation immediately, banding of the pulmonary trunk is first performed to train 
Table 1 Lesions observed in the necropsied hearts that could have militated against surgical success

\begin{tabular}{|c|c|c|}
\hline & $n$ & $\%$ \\
\hline \multicolumn{3}{|l|}{ Contraindications for atrial and arterial switch operations } \\
\hline $\begin{array}{l}\text { Severe Ebstein's malformation with very small trabecular component of the } \\
\text { right ventricle }\end{array}$ & 2 & 8 \\
\hline Atrioventricular septal defect with common atrioventricular junction & 2 & 8 \\
\hline $\begin{array}{l}\text { Straddling and overriding of the tricuspid valve with hypoplasia of the right } \\
\text { ventricle }\end{array}$ & 4 & 16 \\
\hline Ebstein's malformation combined with mitral stenosis & 1 & 4 \\
\hline Subtotal & 9 & 36 \\
\hline \multicolumn{3}{|l|}{ Contraindications for atrial switch and Rastelli procedure } \\
\hline $\begin{array}{l}\text { Severe subpulmonary diaphragmatic fibrous shelf, and restrictive } \\
\text { perimembranous VSD }\end{array}$ & 2 & 8 \\
\hline $\begin{array}{l}\text { Mixed subvalvar and valvar pulmonary stenosis and restrictive } \\
\text { perimembranous VSD }\end{array}$ & 1 & 4 \\
\hline Severe valvar pulmonary stenosis and restrictive ${ }^{\star}$ perimembranous VSD & 2 & 8 \\
\hline Subtotal & 5 & 20 \\
\hline Total & 14 & 56 \\
\hline
\end{tabular}

^Septal defect diameter less than the aortic valve.

VSD, ventricular septal defect.

the left ventricle. These two combinations of surgical procedure have now been expanded by incorporating surgical repair of various associated malformations. ${ }^{16-19}$

These experiences, all of which restore the morphologically left ventricle to its systemic role and thus produce anatomical correction, have now encouraged most centres to reassess their populations of patients with discordant atrioventricular connections. The purpose of our study, therefore, was to evaluate the feasibility of such operative procedures in our own patients with discordant atrioventricular connections, assessing echocardiographic findings in the light of morphological observations.
As yet, we do not have sufficient surgical experience to confirm the validity of our prognostications.

\section{Methods}

We analysed first the morphological features of all the 25 specimens with discordant atrioventricular connections stored in the cardiopathological museum at the Royal Brompton Campus of the National Heart and Lung Institute, Imperial College School of Medicine, London. These had been collected over a period of 25 years. Each specimen was studied to establish any potential morphological contraindications to anatomical correction. We were able to determine the patterns of the major coronary arteries in 20 of these hearts, describing the findings as suggested by McKay et al. ${ }^{20}$ Thus we evaluated the mutual relation of the aortic and pulmonary valvar orifices, the alignment of the facing arterial sinuses, the location of the coronary arterial orifices within the sinuses, and the origin and epicardial course of the coronary arteries.

Those features discovered in the necropsied hearts which might have militated against surgical success were then evaluated in a population of 53 patients with discordant atrioventricular connections examined echocardiographically at the Royal Brompton Hospital between January 1992 and October 1997 (33 males and 20 females, ratio 1.6). The patients had a mean (SD) age of 4.6 (3.5) years. Transthoracic echocardiography had been performed in all, and additional transoesophageal studies
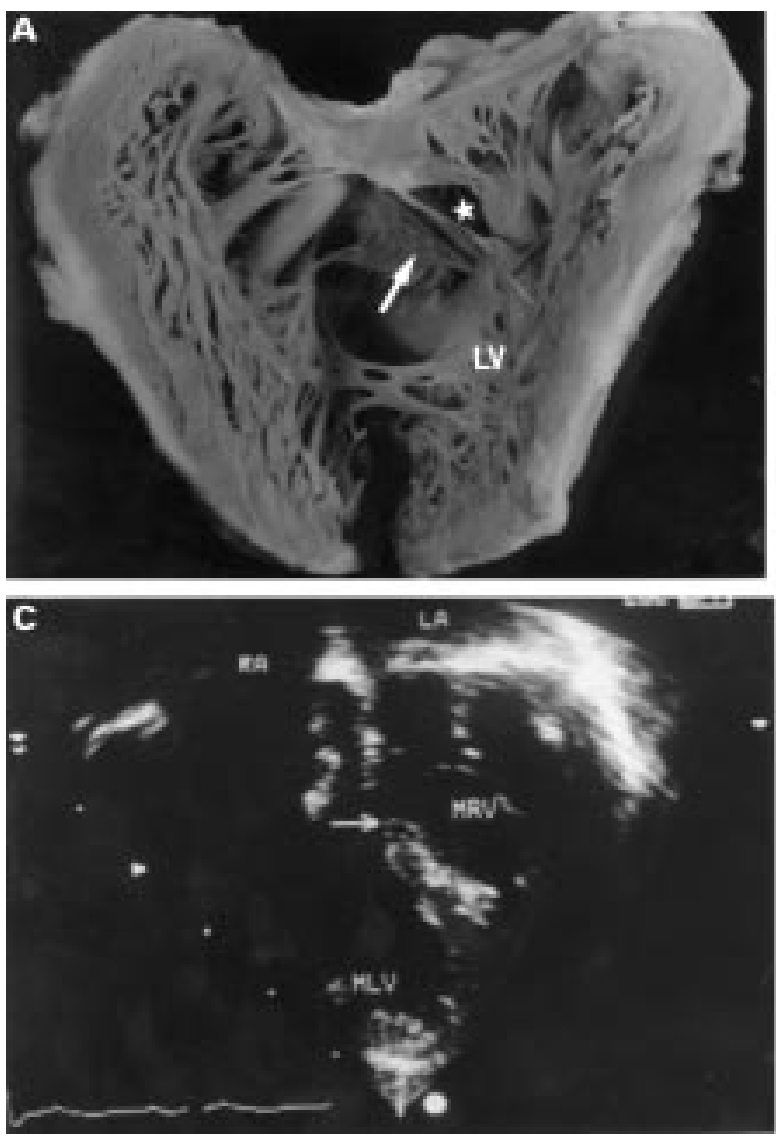

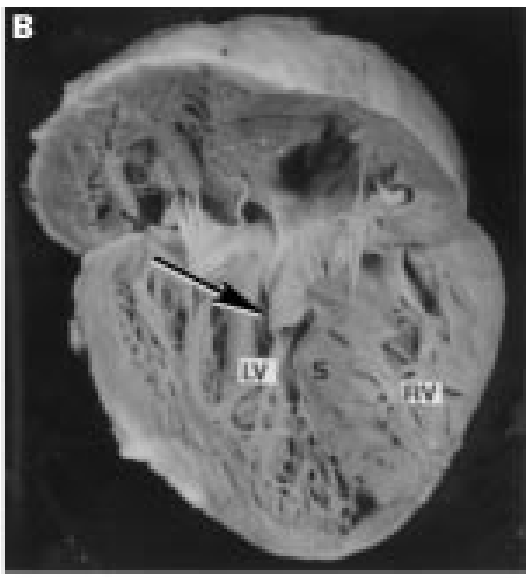

Figure 1 A potential contraindication for combined atrial and arterial switching. This view of the morphologically left ventricle $(A)$ shows a perimembranous septal defect (star) in the inlet portion with straddling of the tricuspid valve (arrow). A section through the same heart (B) shows the straddling (arrow) and overriding of the tricuspid valve, with significant hypoplasia of the right ventricle. The transoesophageal four chamber section from another patient $(C)$ shows the discordant atrioventricular connections, straddling and overriding of the tricuspid valve, and the hypoplasia of the right ventricle. The arrow points to the crest of the ventricular septum. $L A$, left atrium; $L V$, left ventricle; $M L V$, morphologically left ventricle; $M R V$, morphologically right ventricle; $R A$, right atrium; $R V$, right ventricle; $S$, septum. 


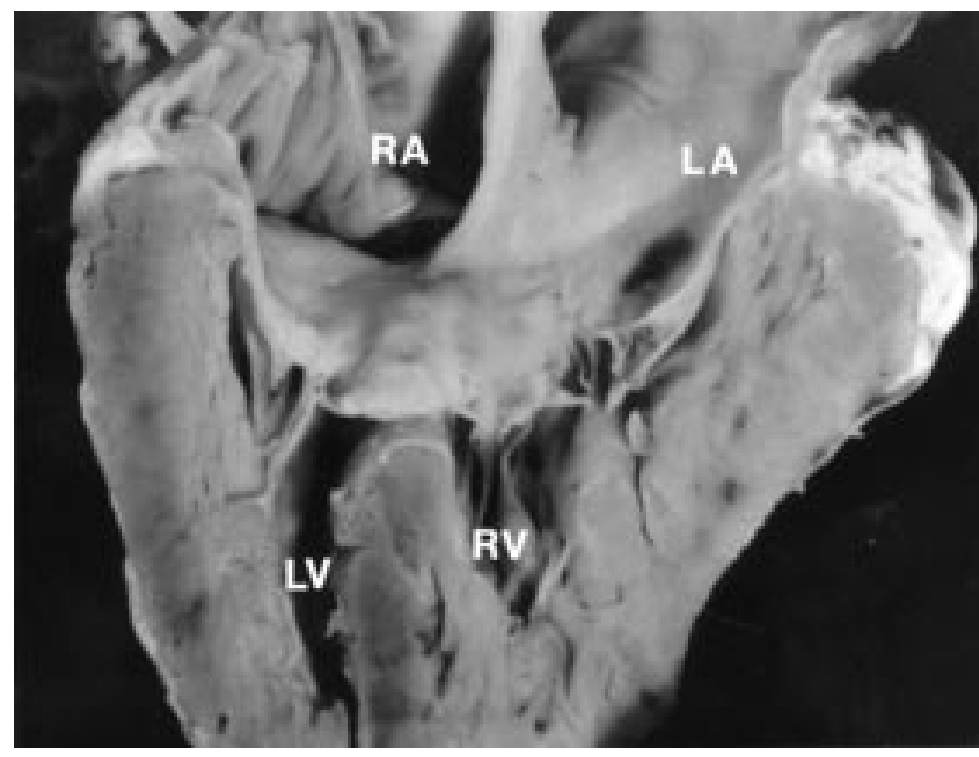

Figure 2 A specimen showing discordant atrioventricular connections combined with a atrioventricular septal defect and a common atrioventricular valve. LA, left atrium; LV, left ventricle; $R A$, right atrium; $R V$, right ventricle.

were performed in seven. Echocardiography was performed using Hewlett-Packard Sonos 1500 and 2000 machines (Hewlett-Packard Inc, Andover, Massachusetts, USA). All images were recorded on tape. The examination included the inferential diagnosis of atrial arrangement (situs) based on the relations of the great vessels relative to the spine within the abdomen. In those undergoing transoesophageal studies, it proved possible to determine the morphology of the atrial appendages directly. The subcostal views in long and short axis, along with the four chamber projection, proved best for establishing the segmental connections. In the interest of brevity, when discussing our findings we shall describe the morphologically left ventricle simply as the left ventricle, and the morphologically right ventricle as the right ventricle, irrespective of their locations in space. We catalogued all the associated anomalies, noting also the position of the heart within the thorax. Some patients were studied on more than one occasion.

\section{Results}

CARDIOPATHOLOGICAL FINDINGS

The 25 specimens were obtained from patients in whom the heart had been left sided in 18 $(72 \%)$, and right sided in seven $(28 \%)$, with the apex pointing to the side of the heart in all. The atrial appendages were of usual arrangement in 23 specimens $(92 \%)$, and showed mirror imagery in two (8\%). In 23 hearts the ventriculo-arterial connections were discordant, with double outlet right ventricle in one and double outlet left ventricle in the other.

We considered that, on basis of the associated lesions, significant impediments to anatomical correction were present in 15 specimens $(60 \%)$ (table 1$)$.

Severe Ebstein's malformation was found in combination with a very small apical trabecular component of the right ventricle in two specimens $(8 \%)$. The ventricular size was only one third of the expected dimensions.

Straddling and overriding of the tricuspid valve (fig 1), again when combined with significant hypoplasia of the right ventricle, was also considered to produce a situation in which anatomical correction would have proven exceedingly difficult. This was found in four hearts $(16 \%)$.

Mitral stenosis, observed in one specimen (4\%), was also considered a contraindication, taking account of the fact that the left ventricle must drive the systemic circulation.

Atrioventricular septal defect with common atrioventricular junction, seen in two hearts $(8 \%)$ (fig 2), was considered a potential contraindication in the present era because of the added complexity in achieving anatomical correction.

A ventricular septal defect was judged to be restrictive (fig 3) when its diameter was significantly less than the diameter of the aortic valve. This finding, seen in five hearts $(20 \%)$ would have precluded the construction of an intraventricular tunnel as part of the Rastelli procedure. It is nearly impossible to enlarge such defects in the setting of the discordant atrioventricular connections without damaging the atrioventricular conduction tissues (fig 3), although
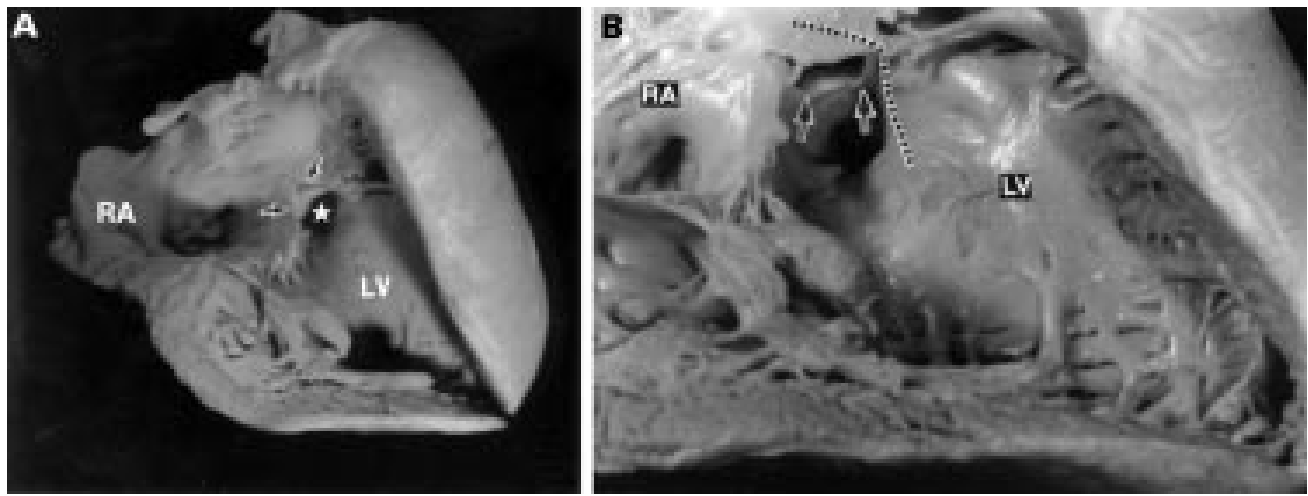

Figure 3 An unequivocal contraindication for the combined atrial switching and Rastelli procedures. This view of the morphologically left ventricle $(A)$ shows a restrictive perimembranous septal defect (star) associated with a subvalvar fibrous shelf. Note that the leaflet of the mitral valve has been cleaved (arrows) and pulled apart. A close up view of the same specimen (B) shows a circumferential fibrous shelf (arrow) causing subpulmonary stenosis. The anticipated course of the atrioventricular conduction bundle (broken line) has been superimposed to illustrate its close relations to the fibrous shelf and the anterior margin of the ventricular septal defect. LV, left ventricle; RA, right atrium. 


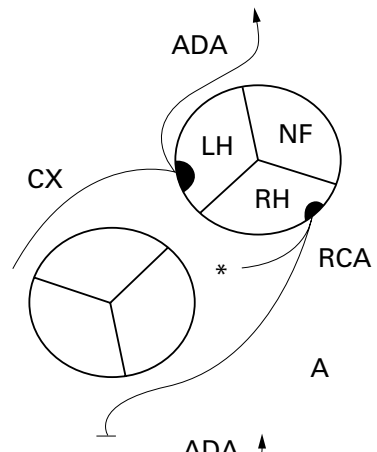

A

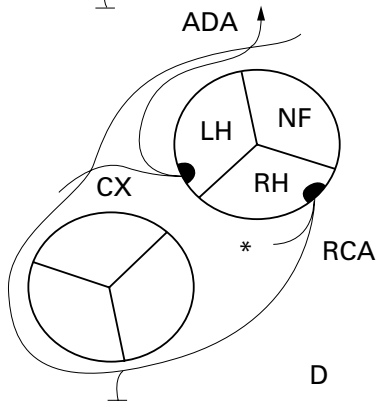

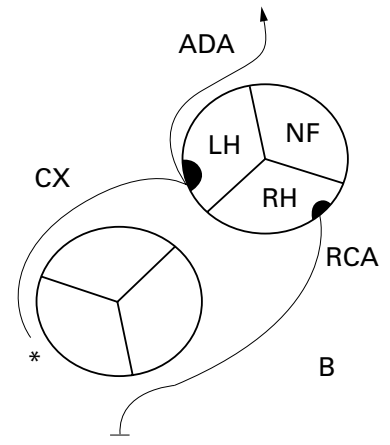

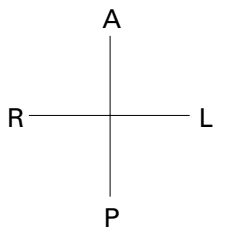

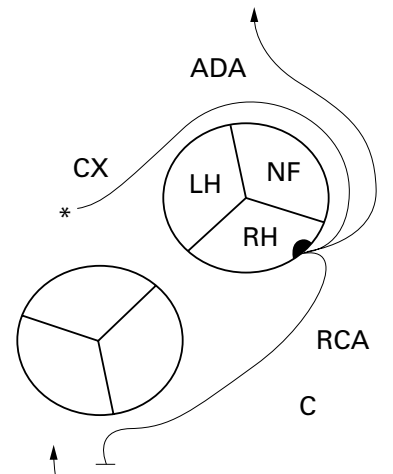

ADA

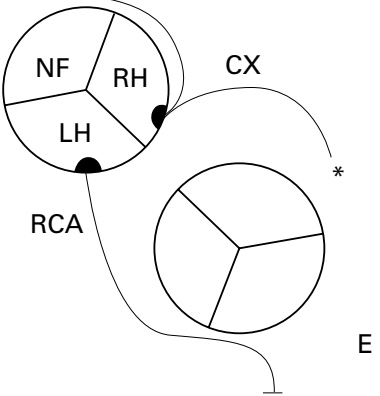

Figure 4 Origins and branching patterns of the coronary arteries in 20 hearts with discordant atrioventricular connections, as would be seen in the echocardiographic parasternal short axis view. (A) to (D) represent specimens with usual atrial arrangement, while $(E)$ represents two specimens with mirror imaged atrial arrangement. $(A)$ The arrangement in seven specimens with the nodal artery arising from the right coronary artery. (B) The arrangement in 13 hearts with the nodal artery originating as a branch of the circumflex artery, or from its distal end. $(C) A$ heart with a solitary arterial orifice in the right hand sinus. (D) A specimen with a short circumflex artery. ADA, anterior descending coronary artery; $C X$, circumflex coronary artery; $L H$, left hand sinus; NF, non-facing sinus; RCA, right coronary artery; $R H$, right hand sinus. Asterisks indicate sinus nodal artery. $A, P, R, L$ : anterior, posterior, right, left, respectively.

some might choose to accept the complication of surgically induced heart block as a lesser evil than the alternatives.

The coronary arterial patterns were studied in 20 hearts (fig 4). Of these, 18 had the usual (solitus) arrangement of the atrial appendages, and two had mirror imagery (inversus). The aorta was leftward and anterior to the pulmonary trunk in all the specimens with the usual atrial arrangement, and rightward and anterior in the specimens with mirror imagery. Abnormal commissural alignment of the valvar leaflets was seen in 11 hearts $(55 \%)$, all having the zone of apposition between the valvar leaflets supporting the facing aortic sinuses deviated toward the right hand sinus. In 18 hearts with the usual atrial arrangement, the artery arising from the right hand sinus (as viewed from the non-facing aortic sinus) supplied the morphologically right ventricle. The anterior descending and circumflex coronary arteries supplying the morphologically left ventricle arose from the left hand sinus. One heart had a solitary orifice in the right hand sinus (fig 4C). In this case, the anterior descending and circumflex coronary arteries originated as a branch of the artery which supplied the morphologically right ventricle. In two hearts with mirror imaged atrial arrangement (fig 4E), the anterior descending and circumflex coronary arteries supplying the morphologically left ventricle arose from the right hand sinus. The morphologically right ventricle was supplied by an artery arising from the left hand sinus. The sinus nodal artery originated as a branch of the circumflex artery in eight specimens, and from its distal end in five (fig 4B). In seven hearts, the artery arose from the right coronary artery (fig 4A). In one heart, the morphologically right coronary artery continued in the atrioventricular groove to end as an anterior diagonal branch, crossing a short circumflex artery (fig 4D). Most of the arterial orifices arose within the aortic sinuses. Four orifices were at the sinutubular junction, and only one orifice was located above the sinutubular junction. None of these patterns was considered to offer any contraindications for anatomical correction, nor were any intramural arterial segments discovered.

On the basis of the abnormalities observed, therefore, we considered that anatomical correction would have proved feasible in 11 specimens $(44 \%)$ by means of combining an atrial switch with either an arterial switch or the Rastelli procedure. Of the four specimens suitable for combined atrial and arterial switching, three would not have required previous banding of the pulmonary trunk. Banding would have been necessary in one specimen with an intact ventricular septum. The remaining seven specimens, all having large ventricular septal defects associated with severe pulmonary stenosis, were considered suitable for correction using the atrial switch combined with a Rastelli procedure.

CLINICAL FINDINGS

The heart was left sided in 29 patients (55\%), right sided in $13(25 \%)$, and centrally located in $11(21 \%)$. The atrial chambers were arranged in usual fashion in 51 patients (96\%), 
Table 2 Lesions observed echocardiographically that could have militated against surgical success

\begin{tabular}{|c|c|c|}
\hline & $n$ & $\%$ \\
\hline \multicolumn{3}{|l|}{ Militating against the combined atrial and arterial switch operations } \\
\hline $\begin{array}{l}\text { Severe Ebstein's malformation with very small trabecular component of the right } \\
\text { ventricle }\end{array}$ & 2 & 3.7 \\
\hline $\begin{array}{l}\text { Straddling and overriding of the tricuspid valve with severe hypoplasia of the right } \\
\text { ventricle }\end{array}$ & 6 & 11.3 \\
\hline Mitral stenosis with hypoplasia of the left ventricle & 1 & 1.8 \\
\hline Atrioventricular septal defect with common atrioventricular junction & 1 & 1.8 \\
\hline Subtotal & 10 & 18.9 \\
\hline \multicolumn{3}{|l|}{ Producing problems for the atrial switch combined with the Rastelli procedure } \\
\hline Valvar pulmonary stenosis and restrictive perimembranous VSD ${ }^{\star}$ & 3 & 5.6 \\
\hline Severe subpulmonary diaphragmatic fibrous shelf and perimembranous VSD* & 3 & 5.6 \\
\hline Subtotal & 6 & 11.3 \\
\hline Total & 16 & 30.2 \\
\hline
\end{tabular}

^Septal defect diameter less than the aortic valve, except in pulmonary atresia VSD, ventricular septal defect. properly selected cases, the failing right ventricle can be rescued by the arterial switch procedure, restoring it to its role as the subpulmonary ventricle. ${ }^{22}$

In the setting of congenitally corrected transposition, deterioration of the systemic morphologically right ventricle is seen most often when associated with tricuspid valvar regurgitation. Systemic ventricular dysfunction, however, is common in the overall population of patients with corrected transposition after childhood, reflecting the inability of the right ventricle to support the systemic circulation over a lifetime. ${ }^{23}$ Such right ventricular dysfunction is increased when there is the need for multiple reoperations for tricuspid valvar replacement, and these procedures themselves carry significant mortality. ${ }^{24}$ Indeed, heart failure owing to right ventricular dysfunction is the main cause of late death in these patients. ${ }^{112526}$ Even patients with uncomplicated congenitally corrected transposition, when followed over the long term, develop tricuspid regurgitation, dysfunction of the right ventricle, and complete atrioventricular block. Only a few patients have been reported to survive beyond the fourth decade. $^{27}$

In this equation, when the few patients living normal lives are contrasted with the much larger proportion destined in time to develop failure of the morphologically right ventricle, it is not unreasonable to support the trend towards anatomical rather than physiological surgical correction, accepting that other options, such as the Fontan procedure, ${ }^{28}$ are also applicable to many, if not most, of the patients.

As far as we can establish, it was Subirana et al who first performed a double switch operation for surgical repair of corrected transposition, ${ }^{29}$ although their attempt was unsuccessful. It was Ilbawi and his colleagues who were the first to report success with the combination of an atrial switch and intracardiac rerouting of the outlet of the left ventricle, coupled with placement of a conduit from the right ventricle to the pulmonary trunk. ${ }^{15}$ Other reports followed rapidly, describing anatomical correction by combining the atrial switch with an arterial switch when the left ventricular outflow tract was unobstructed, or with the Rastelli procedure when there was pulmonary stenosis or atresia. In the latter setting, of course, a large ventricular septal defect is needed to permit construction of an adequate intraventricular tunnel. ${ }^{16-18} 2230$ This is because enlargement of a perimembranous ventricular septal defect in the setting of discordant atrioventricular connections is extremely hazardous owing to the abnormal position of the atrioventricular conduction tissues. ${ }^{9}$

It seems, therefore, that anatomical correction will increasingly become the surgical option of choice for patients with double discordance. In this light, it is important to identify properly those patients in whom the operation can be safely undertaken. In our present study, we considered that while conditions such as a common atrioventricular junction and straddling of the tricuspid valve or severe Ebstein's malformation, when for surgical correction of complete transposition (concordant atrioventricular and discordant ventriculo-arterial connections). ${ }^{21}$ In this setting, recent experience has shown that, in 
combined with significant hypoplasia of the apical component of the right ventricle, might not necessarily be absolute contraindications for anatomical correction, they would have required technically hazardous and extremely long surgical procedures, hampering the chances of successful repair. We recognise that, with continuing improvements, the skilful surgeon will now almost certainly be able to overcome such purely anatomical problems. It is imperative in the early stages of surgical experience, nonetheless, to select patients with adequate anatomy so as to ensure appropriate survival. With increasing surgical experience, therefore, we recognise that our predictions may prove unduly pessimistic.

Fortunately, as far we could judge, the anatomy of the coronary arteries would not have precluded an arterial switch in any of our necropsied hearts, despite the discovery of abnormal commissural alignment in more than half. An intramural origin of the coronary arteries is now the major complicating factor recognised in repair of complete transposition, ${ }^{31}{ }^{32}$ although it can be circumvented in the best hands. This abnormality was not observed among our specimens, but it must surely be anticipated. Other patterns, such as origin from the non-facing sinus, if it exists, would probably produce greater problems.

We acknowledge that a major deficiency of our investigation is its retrospective nature, along with the fact that, as yet, the number of patients undergoing anatomical correction in our own centre is too small to permit validation of our predictions. It is now possible, nonetheless, to recognise all potential contraindications by cross sectional echocardiography, particularly when combined with colour Doppler imaging and transoesophageal imaging. ${ }^{33}{ }^{34} \mathrm{We}$ also anticipate that, with experience gained from patients with complete transposition, it will prove possible to identify any abnormal origins of the coronary arteries, including their intramural location, should this be present. ${ }^{32}$ As we have already discussed, it is also likely to prove that, with increasing experience, many of the problems we presently consider as contraindications can be neutralised. Such clinical experience will also enable us to document accurately features such as hypoplasia of the right ventricle and the size of restrictive ventricular septal defects which, in our study, have been assessed subjectively rather than objectively. In the final analysis, only experience gained in the clinical arena will determine the proportion of patients with discordant atrioventricular connections who will become realistic candidates for anatomical repair, restoring the morphologically left ventricle to its rightful role as the systemic pumping chamber.

We are grateful to Karen McCarthy, Zarlasht Najem, and Vi-Hue Tran for their excellent technical assistance, and to Mrs Christine Anderson for expert secretarial help. We are also indebted to Professor A N Redington and Dr E A Shinebourne, who were involved in the clinical care of many of the patients who were involved in the clinical care of many of the patients studied, and Dr Leon Gerlis, who collected many of the speci-
mens. RHA and SYH are supported by the British Heart Founmens. RHA and SYH are supported by the British Heart Foundation and the Joseph Levy Foundation. During the course of
this investigation CA was a visiting research fellow from Hospithis de Cardiologia Centro Medico Nacional Siglo XXI, Mexico tal de Cardiol
City, Mexico.
1 von Rokitansky CF. Die Defecte der Scheidewande des Herzens. Vienna: Pathologisch-Anatomisch Wilhelm Braumuller, 1875:27-36.

2 Anderson RC, Lillehei CW, Lester RG. Corrected transposition of the great vessels of the heart; a review of 17 cases. Pediatrics 1957;20:626-46.

3 Lev M, Rowlatt UF. Pathological anatomy of mixed levocardia. A review of thirteen cases of atrial or ventricular inversion with or without corrected transposition. Am 7 Cardiol 1961;8:216-63.

4 Schiebler GL, Edwards JE, Burchell HB, et al. Congenital corrected transposition of the great arteries: a study of 33 cases. Pediatrics 1961;27:849-88.

5 Allwork SP, Bentall HH, Becker AE, et al. Congenitally corrected transposition of the great arteries: morphologic study of 32 cases. Am f Cardiol 1976;38:910-23.

6 Craig BG, Smallhorn JF, Rowe RD, et al. Severe obstruction to systemic blood flow in congenitally corrected transposition (discordant atrioventricular and ventriculo-arterial connexions): an analysis of 14 patients. Int f Cardiol 1986; 11:209-17.

7 Anderson RH, Becker AE, Gerlis LM. The pulmonary outflow tract in the classically corrected transposition. 7 Thorac Cardiovasc Surg 1975;69:747-57.

8 Becker AE, Ho SY, Caruso G, et al. Straddling right atrioventricular valves in atrioventricular discordance. Circulation 1980;61:1133-41.

9 Anderson RH, Becker AE, Arnold R, et al. The conducting tissues in congenitally corrected transposition. Circulation 1974;50:911-23.

10 Waldo AL, Pacifico AD, Bargeron LM, et al. Electrophysiological delineation of the specialized A-V conduction system in patients with corrected transposition of the great vessels and ventricular septal defect. Circulation 1975;52: vessels and 435 .

11 Termignon J, Leca F, Vouhé PR, et al. "Classic" repair of congenitally corrected transposition and ventricular septal defect. Ann Thorac Surg 1996;62:199-206.

12 Sano T, Riesenfeld T, Karl TR, et al. Intermediateterm outcome after intracardiac repair associated cardiac defects in patients with atrioventricular and ventriculoarterial discordance. Circulation 1995;92(suppl II):II272-8.

13 Lieberson $\mathrm{AD}$, Schumacher RR, Chidress RH, et al. Corrected transposition of the great arteries in a 73 years old man. Circulation 1969;39:96-100.

14 Connelly MS, Lui PP, Williams WG, et al. Congenitally corrected transposition of the great arteries in adult: functional status and complications. F Am Coll Cardiol 1996;27:123843.

15 Ilbawi MN, DeLeon SY, Backer CL, et al. An alternative approach to the surgical management of physiologically corrected transposition with ventricular septal defect and pulmonary stenosis or atresia. $\mathcal{F}$ Thorac Cardiovasc Surg 1990;100:410-15.

16 Yagihara $\mathrm{T}$, Kishimoto $\mathrm{H}$, Isobe $\mathrm{F}$, et al. Double switch operation in cardiac anomalies with atrioventricular and ventriculoarterial discordance. I Thorac Cardiovasc Surg 1994;107:351-8.

17 Stümper OF, Wright JGC, De Giovanni JV, et al. Combined atrial and arterial switch procedure for congenital corrected transposition with

18 Yamagishi $\mathrm{M}$, Imai $\mathrm{M}$, Hoshino $\mathrm{S}$, et al. Anatomic correction of atrioventricular discordance. F Thorac Cardiovasc Surg 1993;105:1067-76.

19 Karl TR, Weintraub RG, Brizard CP, et al. Senning plus arterial switch operation for discordant (congenitally corrected) transposition. Ann Thorac Surg 1997;64:495502.

20 McKay R, Anderson RH, Smith A. The coronary arteries in hearts with discordant atrioventricular connections. F Thorac Cardiovasc Surg 1996;111:988-97.

21 Ramsay JM, Venables AW, Kelly MJ, et al. Right and left ventricular function at rest and with exercise after the Musventricular function at rest and with exercise after the Mus-
tard operation for transposition of the great arteries. $\mathrm{Br}$ tard operation for transp

22 Cochrane AD, Karl TR, Mee RBB. Staged conversion to arterial switch for late failure of the systemic right ventricle. Ann Thorac Surg 1993;56:854-62.

23 Graham TPJ, Parrish MD, Boucek RIJ, et al. Assessment of ventricular size and function in congenitally corrected transposition of the great arteries. Am $\mathcal{F}$ Cardiol 1983;51: 244-51.

24 Horvath P, Szufladowicz M, de Leval MR, et al. Tricuspid valve abnormalities in patients with atrioventricular discordance: surgical implications. Ann Thorac Surg 1994; 57:941-55.

25 van Son JAM, Danielson GK, Hutha JC, et al. Late results of systemic atrioventricular valve replacement in corrected transposition. I Thorac Cardiovasc Surg 1995; 109:642-53.

26 McGrath LB, Kirklin JW, Blackstone EH, et al. Death and other events after cardiac repair in discordant atrioventricular connections. F Thorac Cardiovasc Surg 1985;90: 711-28.

27 Presbitero P, Somerville J, Rabajoli F, et al. Corrected transposition of the great arteries without associated defects in adult patients: clinical profile and follow up. Br Heart $\mathcal{f}$ 1995;74:57-79.

28 Murari V, Sharma V, Airan B, et al. Morphology of hearts undergoing Fontan repair. Cardiol Young 1998;8:165-71. 
29 Subirana MT, de Leval M, Somerville J. Double outlet right ventricle with atrioventricular discordance. Am 7 Cardiol ventricle with at

30 Di Donato RM, Troconis CJ, Marino B, et al. Combined Mustard and Rastelli operations. An alternative approach for repair of associated anomalies in congenitally corrected transposition in situs inversus. F Thorac Cardiovasc Surg 1992;104:1246-8.

31 Gittenberger-de Groot AC, Sauer U, Oppenheimer-Dekker A, et al. Coronary arterial anatomy in transposition of the great arteries: a morphologic study. Pediatr Cardiol 1983;4(suppl I): 15-24.
32 Pasquini L, Parness IA, Colan SD, et al. Diagnosis of intramural coronary artery in transposition of the great arteries using two-dimensional echocardiography. Circulation 1993; 88:1136-41.

33 Sutherland GR, Smallhorn JF, Anderson RH, et al. Atrioventricular discordance. Cross-sectional echocardiographicmorphological correlative study. Br Heart $f$ 1983;50: 8-20.

34 Saracler M, Gil E, Ozkutlu S. Echocardiography for the diagnosis of congenital cardiac anomalies with multiple lesions. Pediatr Cardiol 1996;17:308-13. 